\title{
Transhepatic approach for cardiac catheterisation in children: initial experience
}

\author{
K A McLeod, A B Houston, T Richens, N Wilson
}

\begin{abstract}
Aim-To assess initial experience of cardiac catheterisation in children by the transhepatic approach where conventional venous access is impossible.

Patients and methods-Percutaneous transhepatic cardiac catheterisation was performed on six occasions in five children (three male) aged 4 to 36 months (mean 17 months). All children had documented femoral venous occlusion and all but one had occlusion of the superior vena cava. Ultrasound was used in five of the six procedures to help identify a large hepatic vein. A $4 \mathrm{~F}$ or $5 \mathrm{~F}$ sheath was introduced into the vein using the Seldinger technique. In the fourth patient, hepatic venous access was obtained immediately without the assistance of ultrasound.

Results-Percutaneous transhepatic catheterisation was successfully performed at all six attempts. Total procedure time ranged from 120 to 200 minutes (mean 138 minutes) and screening time from 14 to 22 minutes (mean 16.8 minutes). A serious complication was encountered in only one patient who had a retroperitoneal bleed after administration of thrombolysis for loss of femoral arterial pulse.

Conclusions-The percutaneous transhepatic technique can provide a safe alternative approach for cardiac catheterisation in children with multiple venous occlusion. The procedure can be performed very simply using the Seldinger technique and equipment normally used for conventional venous cannulation for cardiac catheterisation. (Heart 1999;82:694-696)
\end{abstract}

Keywords: cardiac catheterisation; transhepatic approach; congenital heart defects
There are increasing numbers of children with congenital heart disease in whom conventional venous access for cardiac catheterisation is not possible because of venous occlusion following multiple previous catheterisations or central venous cannulation. The transhepatic approach provides an alternative route for catheterisation. $^{1-3}$ We describe our initial experience in five children.

\section{Methods}

Percutaneous transhepatic cardiac catheterisation was performed on six occasions in five children (three male) aged 4 to 36 months (mean age 17 months). All children had documented femoral venous occlusion and all but patient 4 had occlusion of the superior vena cava. The clinical diagnoses and reasons for catheterisation are shown in table 1 .

All procedures were performed under general anaesthetic. Percutaneous transheptic puncture was performed using a 20 gauge needle (Cook) with a $5 \mathrm{ml}$ syringe, entering the skin below the right subcostal margin approximately midway between the xiphoid sternum and right midaxillary line and directing the needle towards the right atrium. Ultrasound was used in five of the six procedures to help identify a large hepatic vein and guide the needle into the vein. In patient 4 , venous access was obtained immediately without the assistance of ultrasound. As the needle was pushed forward through the liver, constant gentle suction was maintained on the syringe until blood was drawn back. Using fluoroscopic screening, a 0.021 inch guidewire was introduced through the needle and positioned in the right atrium (fig 1). The needle was exchanged for a $4 \mathrm{~F}$ or $5 \mathrm{~F}$ dilator, followed by a $4 \mathrm{~F}$ or $5 \mathrm{~F}$ haemostatic sheath (fig 2). After catheterisation, the sheath was removed and superficial haemostasis obtained by pressure. No coil was placed in the tract between the hepatic vein and

Table 1 Diagnoses and reasons for catheterisation

\begin{tabular}{|c|c|c|c|c|c|c|c|}
\hline Patient & Age (months) & Weight $(\mathrm{kg})$ & Diagnosis & Reason for catheterisation & $\begin{array}{l}\text { Procedure time } \\
\text { (min) }\end{array}$ & $\begin{array}{l}\text { Screening } \\
\text { time (min) }\end{array}$ & $\begin{array}{l}\text { RAP } \\
(m m \mathrm{Hg})\end{array}$ \\
\hline 1 & 4 & 4.5 & $\begin{array}{l}\text { Repaired total anomalous pulmonary } \\
\text { venous drainage, tetralogy of Fallot }\end{array}$ & $\begin{array}{l}\text { Balloon angioplasty of pulmonary } \\
\text { venous stenosis }\end{array}$ & 180 & 21 & 10 \\
\hline 2 & 35 & 11.4 & $\begin{array}{l}\text { Pulmonary atresia, intact septum, } \\
\text { pulmonary conduit }\end{array}$ & $\begin{array}{l}\text { Evaluation of gradient across } \\
\text { pulmonary conduit }\end{array}$ & 120 & 22 & 11 \\
\hline 3 & 27 & 11.9 & $\begin{array}{l}\text { Complete transposition, Senning, tricuspid } \\
\text { regurgitation, right heart failure }\end{array}$ & $\begin{array}{l}\text { Evaluation of pulmonary arterial } \\
\text { pressure and baffle leak }\end{array}$ & 130 & 14 & 12 \\
\hline 3 & 36 & 12.7 & & $\begin{array}{l}\text { Evaluation of pulmonary and left } \\
\text { ventricular pressures }\end{array}$ & 200 & 22 & 13 \\
\hline 4 & 5 & 5 & $\begin{array}{l}\text { Ventricular septal defect, repaired } \\
\text { coarctation, hypoplastic left ventricle, } \\
\text { pulmonary band }\end{array}$ & $\begin{array}{l}\text { Evaluation of pulmonary arterial } \\
\text { pressure and gradient across } \\
\text { pulmonary band }\end{array}$ & 140 & 14 & 10 \\
\hline 5 & 14 & 6.4 & $\begin{array}{l}\text { Repaired tetralogy of Fallot with absent } \\
\text { pulmonary valve }\end{array}$ & $\begin{array}{l}\text { Evaluation of gradient across } \\
\text { pulmonary conduit. }\end{array}$ & 125 & 18 & 8 \\
\hline
\end{tabular}

Patient 3 underwent two transhepatic catheterisations. 


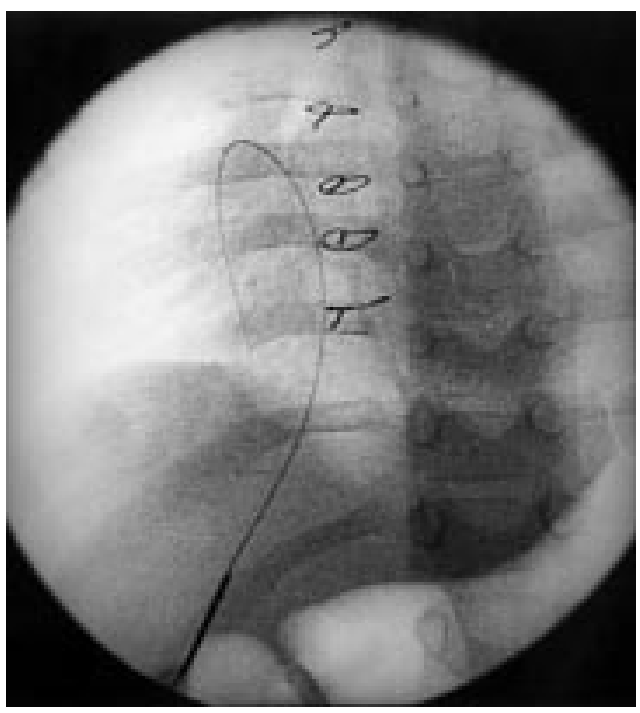

Figure 1 Seldinger technique for transhepatic catheterisation. A large hepatic vein is cannulated and a guide wire introduced through the needle into the right atrium.

liver capsule. Following the procedure, blood pressure and heart rate were monitored non-invasively until the following morning. Abdominal ultrasound was only performed if clinical observations suggested retroperitoneal haemorrhage.

\section{Results}

Percutaneous transheptic catheterisation was successfully performed at all six attempts. In patient 2, transatrial puncture for intervention to relieve pulmonary venous stenosis was unsuccessful, but this was because previous atrial surgery had caused a very thick atrial septum and not because of any deficiency of the transhepatic approach.

Total procedure time ranged from 120 to 200 minutes (mean 138 minutes) and screening time from 14 to 22 minutes (mean 16.8 minutes).

In patient 3 (second procedure) there was difficulty in introducing the sheath through the liver capsule and into the hepatic vein, possibly exacerbated by the angle of entry. The problem was overcome by using a $4.5 \mathrm{~F}$ sheath with a fortified core. No other complications were encountered during the procedures. One patient (case 4) had problems with bleeding after catheterisation. Simultaneous left heart catheterisation had been performed by a femoral artery approach and the patient had received tissue plasminogen activator (tPA) because of an absent foot pulse following catheterisation. One hour after the start of the tPA infusion, she developed pallor, tachycardia, and hypotension. Abdominal ultrasound confirmed a large retroperitoneal bleed. The tPA was stopped and improvement occurred following a blood transfusion. The bleeding settled spontaneously. No complications were encountered in any of the other patients after the catheterisations.

\section{Discussion}

The percutaneous transhepatic approach was first used for cholangiography and portal

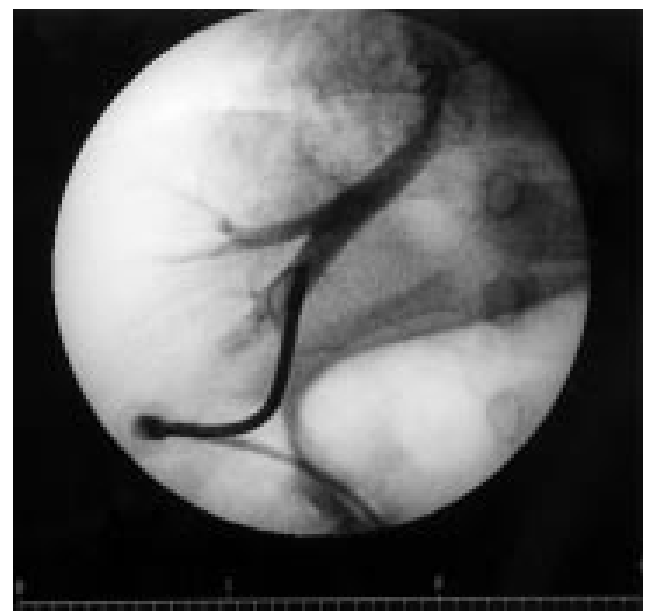

Figure 2 The guide wire has been exchanged for a $4 \mathrm{~F}$ sheath. Injection of contrast through the sheath confirms its position in the hepatic vein.

venous cannulation for procedures such as sclerosing of oesophageal varices. ${ }^{45}$ The technique has also been used for patients requiring long term indwelling central venous catheters for whom other venous access has become impossible. ${ }^{6}$ In 1995, Sommer et al and Shimet et al described the use of the percutaneous transhepatic technique as an alternative approach for cardiac catheterisation in children. ${ }^{12}$ Both used the Neff percutaneous access set, specifically designed for percutaneous cholangiography or nephrostomy and fluoroscopy with injection of contrast to determine when the vein was entered. Our approach is simply to use the Seldinger technique and equipment that would normally be used in the catheter laboratory for femoral or subclavian venous cannulation. We found that ultrasound gave satisfactory and helpful guidance for hepatic venous cannulation, reducing screening time and exposure to radiation. In one patient the vein was immediately cannulated blind with no need for ultrasound and it may be that as operator experience increases, the need for ultrasound guidance is reduced.

The absolute risk of intraperitoneal or retroperitoneal haemorrhage is not certain and will only become clear once more transheptic procedures are performed. ${ }^{7}$ Potentially the risk is greater the larger the sheath used. We did not implant a coil on removal of the sheath and we only encountered a clinically significant bleed in one patient who had been given tPA. It might be advisable to avoid simultaneous left heart catheterisation where possible.

In conclusion, the percutaneous transhepatic technique can provide a safe alternative approach for cardiac catheterisation in children with multiple venous occlusion. The procedure can be performed very simply, using the Seldinger technique and equipment normally used to obtain more conventional venous cannulation for cardiac catheterisation.

1 Shim D, Lloyd TR, Cho KJ, et al. Transhepatic cardiac catheterisation in children. Evaluation of efficacy and safety. Circulation 1995;92:1526-30.

2 Sommer RJ, Golinko RJ, Mitty HA. Initial experience with percutaneous transhepatic cardiac catheterisation in infants and children. Am $\mathcal{F}$ Cardiol 1995;75:1289-91. 
3 Johnson JL, Fellows KE, Murphy JD. Transhepatic central venous access for cardiac cathterisation and radio$\log$

4 Olbert F, Gaudernak T, Meiss F. Percutaneous transhepatic cholangiography. Radiol Clin Biol 1972;41:453-65.

5 Viamonte M, Perieras R, Russell E, et al. Selective catheterisation of the portal vein and its tributaries. Radiology 1975 ,
114:457-60.

6 Azizkan RG, Taylor LA, Jaques PF, et al. Percutaneous translumbar and transhepatic inferior vena caval catheters for prlonged vascular access in children. $\mathcal{F}$ Pediatr Surg 1992;27:165-9.

7 Erenberg FG, Shim D, Beekman RH. Intraperitoneal haemorrage with transhepatic catheterisation: a report of two cases. Cathet Cardiovasc Diagn 1998;43:177-8.

\section{IMAGES IN CARDIOLOGY}

\section{Radiological findings in total anomalous pulmonary venous connection}

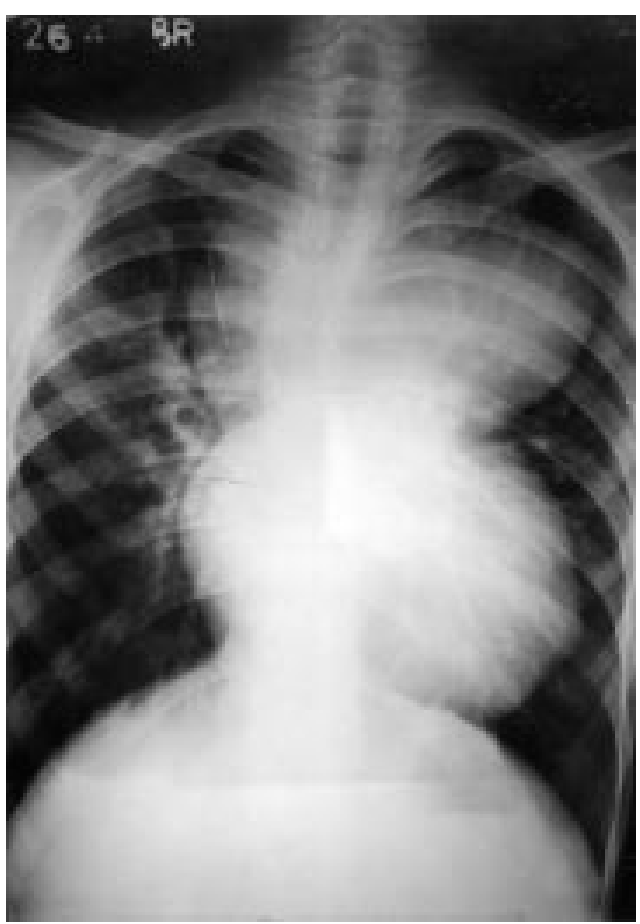

A 22 year old man had total anomalous pulmonary venous connection to the left vertical vein, which drained into the left brachiocephalic vein. He had cyanosis and clubbing. There was no cardiomegaly. Tricuspid flow murmur was absent. Chest radiography in the postero-anterior view showed a "figure of eight" or "snowman's" appearance. The upper half of the figure of eight was formed by the dilated superior vena cava on the right side, left brachiocephalic vein in the top, and the dilated vertical vein on the left side. The lower portion of the figure of eight was formed by the dilated right atrium and ventricle. He had dilated proximal pulmonary arteries with peripheral pruning of pulmonary vasculature, suggesting pulmonary vascular obstructive disease. No surgery was offered.

K M KRISHNAMOORTHY 